\section{Aspectos éticos de la conducta del médico ante personas en huelga de hambre: opinión del Departamento de Ética del Colegio Médico de Chile}

\author{
SOFÍA P. SALAS ${ }^{1,2}$, ANAMARÍA ARRIAGADA ${ }^{1,3}$, \\ LIONIEL BERNIER VILLARROEL ${ }^{1,4}$, MAURICIO BESIO ${ }^{1,5}$, \\ CONSTANZA MICOLICH ${ }^{1,6}$, ADELIO MISSERONI ${ }^{1, a}$, \\ FERNANDO NOVOA SOTTA ${ }^{1,7}$, RODRIGO A. SALINAS ${ }^{1,8}$ \\ CARLOS Y. VALENZUELA ${ }^{1,9}$, GLADYS BÓRQUEZ ESTEFÓ ${ }^{1,10}$
}

\section{Ethical aspects of the doctors' behavior towards people on hunger strike: position paper from the Ethics Department of the Chilean Medical Association}

Every so often, in Chile there is a discussion about the role of physicians in the care of people on hunger strike (HS). In this document, we review the ethical aspects of health care for persons in HS, aiming to provide guidelines to medical doctors who are required to attend them. First, we make an important distinction between HS and suicide, since the former is used as a protest and denunciation tool, while suicide seeks deliberately to end a life. Then we describe the three roles that the health professional can fulfill: as a treating doctor, as an expert or as an official of a prison. The respect for the autonomy and dignity of the person in HS must prevail whatever the role of the physician. Therefore, we maintain that under no circumstances, people who have autonomously decided to be in HS should be fed by force. Due to the complexity of the issue, we make special considerations about the management of minors and the non-competent persons in HS. In conclusion, we adhere to the principles that inspire the Declaration of Malta, which indicate that it would be preferable to "allow a person on hunger strike to die in dignity, rather than subjecting them to repeated interventions against their will".

(Rev Med Chile 2018; 146: 1059-1063)

Key words: Ethics; Enteral Nutrition; Hunger; Strikes, Employee.

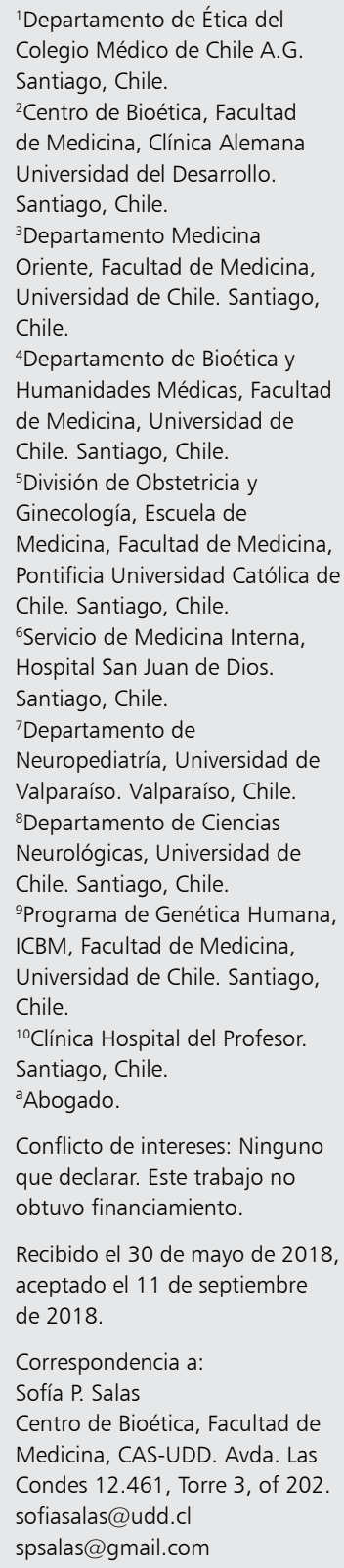

$\mathrm{D}$ ebido a diversos casos que han suscitado interés en los medios, cada cierto tiempo surge en Chile la discusión sobre los aspectos éticos asociados a la atención sanitaria de personas en huelga de hambre $(\mathrm{HH})^{1}$. Con independencia de los motivos que lleven a esa persona o grupo de individuos a asumir el ayuno como medida de presión, dicha acción no deja indife- rente a nadie y menos aún a los médicos, quienes suelen ser llamados a intervenir profesionalmente. $\mathrm{La}$ atención de personas en $\mathrm{HH}$ tiene muchas aristas, puesto que sus potenciales consecuencias afectan no solo la atención sanitaria, sino que también al sistema judicial, la legislación vigente, los compromisos asumidos como país respecto de los derechos humanos y pactos internacionales que 
son vinculantes. Dicho lo anterior, en el presente artículo nos limitaremos a analizar los aspectos éticos de la atención sanitaria a personas en $\mathrm{HH}$. La preocupación del Departamento de Ética del Colegio Médico de Chile es reflexionar y entregar directrices a nuestros colegiados para abordar adecuadamente las peticiones que las personas en huelga de hambre y la sociedad nos hacen, en virtud de nuestro conocimiento y del rol de nuestra profesión en la comunidad. Dejaremos fuera de este análisis las consideraciones relacionadas con los motivos de la huelga, puesto que creemos que estos exceden al ámbito de competencia del profesional sanitario.

\section{Concepto de huelga de hambre y su diferencia con el suicidio}

La huelga de hambre consiste en la abstinencia voluntaria de ingesta de alimentos o líquidos por un período de tiempo definido o no, utilizada como una herramienta de denuncia y protesta para reivindicar el cumplimiento de algún derecho, eliminar reglas o normas consideradas ilegítimas o injustas por el sujeto que la realiza, pretendiendo así modificar una determinada disposición de la autoridad, un grupo o la comunidad, arriesgando con ello la propia vida y salud ${ }^{1}$. Tal como señala Precht en su revisión, un caso paradigmático de huelga de hambre fue la de Gandhi, considerada como un acto de "no violencia activa", donde el huelguista requiere atraer la atención pública y así presionar a la autoridad para lograr su objetivo de cambiar la situación que considera injusta ${ }^{2}$.

Las características esenciales de la $\mathrm{HH}$ son: "la decisión voluntaria" de privarse del alimento que pudiere incluso conducir hasta la muerte; "la finalidad" de conseguir el reconocimiento efectivo de un derecho juzgado, conculcado o no admitido; "el procedimiento" de presión sobre una persona o una institución causante de la injusticia reclamada y "la táctica" de dar la máxima publicidad posible a la acción huelguista, puesto que sin esta publicidad no se lograrían los fines buscados ${ }^{1}$.

Es necesario distinguir la huelga de hambre de la conducta suicida. En el suicidio, el sujeto comete un acto para poner fin a su vida, en la huelga de hambre se intenta presionar a fin de obtener lo reclamado; la muerte, a pesar de ser una consecuencia posible del ayuno prolongado, no es buscada como un fin en sí misma, sino que es el riesgo que libremente las personas en $\mathrm{HH}$ asumen en pos del objetivo que han definido como prioritario $^{1}$. No obstante, debemos reconocer que algunos defienden la idea que la $\mathrm{HH}$ sería un acto reprobable, puesto que implica un atentado directo contra la vida del huelguista, considerándola como un "suicidio intencional"3.

\section{Consideraciones éticas}

La persistencia del ayuno implica riesgos ciertos para la vida y la salud de los individuos, lo que tensiona dos bienes en conflicto: el deber para con la vida y el derecho a la libertad y autodeterminación de las personas. Es interesante señalar que según la jurisprudencia chilena, diversos fallos consideraron a la $\mathrm{HH}$ como un inaceptable atentado contra la vida humana, por lo que los jueces ordenaron la alimentación forzosa de los huelguistas, al considerar que la vida es un bien indisponible ${ }^{1}$. Como expondremos a continuación, creemos que desde el punto de vista de la ética médica, no procede la alimentación forzosa de personas que autónomamente han iniciado una $\mathrm{HH}$. Esta visión es concordante con lo propuesto por la Declaración de Malta de la Asociación Médica Mundial ${ }^{4}$.

A primera vista, parecería justificable que el médico enfrentado a la $\mathrm{HH}$ intente por todos los medios restablecer la salud del huelguista, incluso alimentándolo contra su voluntad. Sin embargo, pensamos que la existencia del individuo no se agota en su vida puramente biológica, sino que comprende también una vida biográfica, donde radican las creencias, valores, expectativas, afectos y otros aspectos que constituyen la individualidad personal y que se manifiesta a través del respeto del principio de autonomía o en la concepción kantiana de dignidad humana. Por lo tanto, alimentarlo en contra de su voluntad no solo vulnera su autonomía, sino que sería un acto malifecente, porque puede dañarlo en su dimensión espiritual o física, si se lo alimenta mediante el uso de la fuerza. En este sentido, consideramos que la valoración de los riesgos y beneficios de la alimentación forzada debe incluir no solo los aspectos físicos o biológicos, sino que también la dimensión espiritual de la persona en $\mathrm{HH}$. Por lo tanto, cada decisión médica debe considerar toda 
esa complejidad y proponer solo las intervenciones consentidas por el individuo, respetando su rechazo a la alimentación. Para esto, debe cumplirse con todas las formalidades de un rechazo válido a un tratamiento, es decir información, voluntariedad y competencia, y esta expresión de su voluntad debe quedar consignada ya sea en la ficha clínica o en un documento específico.

\section{Roles del médico ante la persona en huelga de hambre}

Debemos distinguir los distintos ámbitos en que los médicos interactúan con personas en $\mathrm{HH}$. Pueden ser requeridos en el marco de una relación médico paciente, en otras como peritos, o como médicos de una institución carcelaria. Estos roles pueden colisionar con nuestra responsabilidad primaria e irrenunciable, que es la salud de la persona.

\section{El médico como tratante}

Antes o luego de iniciada una huelga de hambre, los huelguistas pueden requerir de la asistencia de un médico, ya sea para tratar dolencias previas o sintomatología secundaria a la $\mathrm{HH}$. Estaríamos entonces en una relación médico-paciente propiamente tal, que exige una atención privada, confidencial, sin coerción física, en un ambiente adecuado y una escucha atenta y respetuosa.

Es necesario preguntarse si el médico en este tipo de relación debe o no intentar que el ahora paciente acepte medidas que reviertan su condición de déficit nutricional o deshidratación. El médico debe explicarle claramente su situación de salud, los riesgos de sus decisiones, las medidas alternativas existentes y ayudarle a ponderar las consecuencias de su negativa e implementar las medidas consensuadas. Es legítimo en este espacio intentar persuadir al paciente, pero sin ejercer presión sobre su decisión. Debemos recordar que el respeto a su autonomía se funda en que es él, y no el médico, quien conoce los fines, propósitos, anhelos y preocupaciones de su vida, y un médico prudente las debe considerar para proponer una intervención. Es también posible, y no criticable, que un médico prefiera retirarse de la atención si no es capaz de respetar la decisión del paciente, procurando la concurrencia de otro médico dispuesto a hacerlo.
La comunicación frecuente entre el médico y el paciente en $\mathrm{HH}$ es esencial. Debe cerciorarse a diario si quiere continuar con la $\mathrm{HH}$ y qué desea que se haga cuando ya no pueda comunicarse de manera comprensible. El médico debe identificar si la persona está dispuesta, si sus exigencias son rechazadas, a continuar con el ayuno incluso hasta la muerte. La realimentación es éticamente aceptable solo con el consentimiento explícito de la persona en huelga de hambre. En esta circunstancia, la alimentación se debe iniciar según un protocolo apropiado para el estado fisiológico de la persona. Aplicar, dar instrucciones o ayudar a la alimentación forzada contra un rechazo informado y voluntario es injustificable, aunque signifique su muerte.

\section{El médico como perito}

La HH es un fenómeno social que preocupa a todos. Las autoridades se sienten amenazadas, ya que un efecto ominoso en los ayunantes puede afectar su imagen política y el orden social. Se inicia así un espacio de negociación delicado entre la autoridad y la persona en $\mathrm{HH}$. Se hace necesaria una monitorización y evaluación constante del bienestar físico y mental de los participantes del ayuno, y ahí se necesita un profesional con conocimientos en salud y suficiente legitimidad para cumplir con la labor de perito. El médico podrá ser convocado en esa calidad por la autoridad competente, por el paciente, su familia o por alguna de las agrupaciones que lo representan. En estos casos, el médico debe atenerse a los requerimientos éticos que implica el peritaje. Su función es recabar datos, evaluar la condición física y psicológica de los ayunantes y no ocuparse de intervenciones preventivas o curativas. El médico en situación de perito debe informar al individuo del rol que va a desempeñar, explicar que lo indagado no guarda relación con prevención ni curación de su condición de salud, y que realizará un informe que será conocido por los mandantes. El secreto médico obliga al facultativo que desempeña la labor de perito a no revelar más de lo estrictamente necesario para la realización del informe pericial, el cual solo podrá ser entregado a quienes tuvieran derecho a él, todo ello con el consentimiento del interesado. Esto es concordante con el Art. 71 del Código de Ética del Colegio Médico, que señala que "los facultativos que desarrollen actividades de carácter médico legal, de control o de auditoria, deberán 
comunicar expresamente a la persona involucrada en la diligencia respectiva, la naturaleza de la función que realizan y las posibles consecuencias que para el afectado conlleve su gestión"s. En el cumplimiento de su labor, un perito debe certificar fielmente la realidad observada, sin alterar en uno $\mathrm{u}$ otro sentido el reporte del estado de salud de la persona en HH. Esto es coherente con el Art. 12 de nuestro Código: "El médico debe obrar siempre con honradez y buena fe. No ha de afirmar o negar con falsedad, hacer citas inexactas o tendenciosas, ni hacer certificaciones falsas".

\section{El médico como funcionario de la institución carcelaria}

Una función que puede ser conflictiva es la del médico funcionario de una institución, cuyos objetivos pudieran no coincidir con los de la profesión médica. Esta es la situación de un médico de gendarmería, quien debe velar por la salud y bienestar de los prisioneros, incluyendo aquellos en $\mathrm{HH}$.

La responsabilidad del Estado en recintos carcelarios es garantizar la seguridad e integridad de los prisioneros. Los funcionarios médicos tienen el deber de realizar las acciones preventivas y curativas de los internos, y deben cumplir con los objetivos de la institución. En algún momento, sus superiores les pueden solicitar que impongan a quienes participan de una $\mathrm{HH}$, alimentación, hidratación o medicación forzada ${ }^{6}$. Se produce entonces aquí un conflicto, pues los médicos no deben imponer intervenciones a sus pacientes, aun cuando estas sean solicitadas por sus superiores. Un médico nunca debe renunciar a los valores y principios de su profesión y bajo ninguna circunstancia puede imponer una conducta a sus pacientes.

\section{La persona no competente en huelga de hambre}

En ocasiones, el médico puede ser requerido para tratar a una persona en $\mathrm{HH}$ que no tiene la capacidad suficiente para tomar decisiones de manera autónoma, lo que puede ocurrir como consecuencia de la misma $\mathrm{HH}$ o por alguna condición previa. Si es el primer encuentro que el profesional tiene con esta persona y, por lo tanto, no tiene certeza de que participaba en la $\mathrm{HH}$ en forma libre, es aconsejable que se le apoye con los aportes nutricionales necesarios para que, una vez restablecida la conciencia, el médico pueda evaluar si la persona ha decidido la huelga de hambre libre de cualquier presión externa ${ }^{7}$. Si el médico confirma que esa persona no era competente para tomar decisiones autónomas, no se le puede permitir que ponga su vida en peligro, por lo que si no logra persuadirlo, deberá alimentarlo.

\section{Huelga de hambre en menores de edad}

Los aspectos éticos de la $\mathrm{HH}$ en menores de edad, como la que realizaron hace un par de años estudiantes secundarios de Santiago de Chile en protesta por reformas educacionales, requieren abordar el interés superior del niño, su capacidad de otorgar consentimiento, además de considerar el rol de los padres o tutores, especialmente cuando estos no apoyan la huelga de sus hijos. En estos casos resulta pertinente tener en cuenta la doctrina del "menor maduro" y evaluar el grado de competencia que tiene para tomar estas decisiones de manera autónoma ${ }^{8}$. Dado lo complejo del tema, consideramos que se justifica realizar un trabajo en profundidad sobre esta materia.

\section{Conclusiones}

La huelga de hambre es una situación especial que compromete y tensiona a toda la sociedad, ya que uno de sus principales objetivos es usarla como medio para conseguir diversos logros. A los médicos, que son requeridos de varias maneras para interactuar con aquellos que decidieron ese ayuno, no les corresponde juzgar la licitud de la conducta, sino que evaluar en qué condiciones su ayuda es solicitada y en qué medida les corresponde participar.

El médico no puede olvidar ni renunciar a su obligación ética. Si actúa como médico tratante, su atención debe cumplir todas las condiciones de esa prestación. Si actúa como perito, también debe cumplir las condiciones éticas establecidas por nuestra orden para aquellas formas especiales de ejercicio de la profesión. Si está en una situación de conflicto de intereses, debe siempre resolverlo teniendo en claro cuál es su obligación primaria y los límites de su actuar, que en definitiva están dados por la autonomía de los pacientes. En este 
sentido, y dado los argumentos éticos expuestos, como Departamento de Ética del Colegio Médico adherimos a los principios éticos que inspiran la Declaración de Malta ${ }^{4}$, que establece que "la alimentación forzada nunca es éticamente aceptable. Incluso con la intención de beneficiar, la alimentación con amenazas, presión, fuerza o uso de restricción física es una forma de trato inhumano y degradante". También señala que sería preferible "permitir que una persona en huelga de hambre muera en dignidad, antes que someterla a repetidas intervenciones en contra de su voluntad".

\section{Referencias}

1. Precht J, Faundes JJ. Legitimidad de la huelga de hambre. Un debate sobre el derecho a la vida y la dignidad humana. Estudios Constitucionales 2013; 11 (2): 333-68.

2. Gandhi L. Concerning Violence: The Limits and Circulations of Gandhian “Ahisma” or Passive Resistance. Cultural Critique 1996-1997; 35: 105-47.

3. Miranda Montecinos A, García-Huidobro Correa J, Contreras-Aguirre S. La huelga de hambre como suicidio intencional. Una propuesta de valoración moral desde la tradición central de la ética. Pers Bioét 2015; 19 (1): 64-79. DOI: 10.5294/pebi.2015.19.1.6.

4. Asociación Médica Mundial. "Declaración de Malta sobre las Personas en Huelga de Hambre", adoptada en la 43a Asamblea Médica Mundial en Malta, Noviembre 1991. Última revisión efectuada en la 57a Asamblea General de la Asamblea Médica Mundial en Pilanesberg Sudáfrica, Octubre 2006, AMM. Disponible en: http:// www.wma.net/es/30publications/10policies/h31/index. html (Revisado el 7 de mayo de 2018).

5. Colegio Médico de Chile AG, Código de Ética 2013. Editado e impreso por Ediciones Tierra Mía Ltda. Santiago de Chile. Disponible en http://www.colegiomedico.cl/ wp-content/uploads/2016/09/Codigo-de-Etica-Colegio-Medico-Chile-2013.pdf (Fecha de acceso: 22 de mayo de 2018).

6. Xenakis SN. Ethics Dilemmas in Managing Hunger Strikes. J Am Acad Psychiatry Law 2017; 45 (3): 311-5.

7. Reeves R, Tamburello AC, Platt J, Tepper D, Edelman K. Characteristics of Inmates Who Initiate Hunger Strikes. J Am Acad Psychiatry Law 2017; 45 (3): 302-10.

8. Bórquez B, Montero A, Riquelme E, San Martín C, Valenzuela S. Huelga de hambre en adolescentes: un desafío ético para el equipo de salud. Revista de Bioética y Derecho 2013; 27: 3-12. 